\section{P3.402 EFFECT OF A TAILORED INTERVENTION PACKAGE ON HIV-1 ACOUISITION AMONG YOUNG FEMALE SEX WORKERS IN OUAGADOUGOU, BURKINA FASO}

doi:10.1136/sextrans-2013-051184.0855

II T Traore, 'M N Hema, ${ }^{1,1} \mathrm{~N}$ Meda, ${ }^{2} \mathrm{~K}$ Konate, ${ }^{1} \mathrm{~F}$ Some, ${ }^{2} \mathrm{~W}$ Bazie, ${ }^{3} \mathrm{P}$ Mayaud, 4,5P Van De Perre, ${ }^{4}, 5 \mathrm{~N}$ Nagot. 'University of Ouagadougou, Ouagadougou, Burkina Faso, ${ }^{2}$ Centre Muraz, Bobo-Dioulasso, Burkina Faso; ${ }^{3}$ London School of Hygiene and Tropical Medicine, London, UK; ${ }^{4}$ University of Montpellier, Montpellier, France; ${ }^{5}$ Unité INSERM U1058, Montpellier, France

Background Female Sex Workers (FSWs) represent a major core group of HIV transmission in West Africa, but little data is available on the impact of tailored intervention packages on HIV-1 incidence in this population.

Method HIV-seronegative young women aged 18-25 years, living in Ouagadougou, reporting at least 3 sexual contacts per week and 3 different sexual partners during the last 3 months, and not pregnant were enrolled in a prospective cohort. At each 3-months follow-up visit for a minimum period of 12 months, data on sexual behaviour, HIV-1 and HSV-2 serologies and pregnancy testing were collected. The intervention used a tailored prevention-and-care integrated approach, with repeated peer-led HIV/STI education sessions, condoms provision, and medical care. HIV incidence was compared with an expected incidence based on baseline data among FSW and data from the national 2010 DHS. In Ouagadougou, 2.5\% (95\% CI: $1.5-3.4)$ of women and 3.4\% (95\% CI: 1.3-5.5) of FSW clients were HIV-1 infected.

Results At screening, HIV prevalence among eligible women was $9 \%(55 / 638)$, and 321 women were enrolled. The median weekly number of sexual partners (clients and regular partners) was 3 (IOR: $2-5$ ). During follow-up, $86 \%$ of participants completed 12 -months follow-up and no woman seroconverted for HIV-1 (0/405 personyears, 95\% CI: $0-0.03$ ). The mean number of regular partners decreased during the intervention (from 2 to $1, p<0.001$ ). Adjusted consistent condom use remained consistently very high with clients between $97 \%$ and $99 \%$ ), and did not increase with regular partners (from 64 to $62 \%$ ). The incidence of HSV-2 was 11/100 person-years (95\% CI: $7-15)$, and the pregnancy rate was $28 / 100$ person-years (95\% CI: 23-32). The expected HIV-1 incidence in this group was 1.23/100 person-years (95\% CI: $1.02-1.46)$

Conclusion Through an impact on the number of regular partners, this tailored intervention package markedly reduced HIV incidence to virtual elimination.

\section{P3.403 KNOWLEDGE, OPTIMISM REGARDING HIV/AIDS AND SELF- EFFICACY IN CONDOM USE OF THE MALE SEX WORKERS IN THE CITY OF LISBON: THE RESULTS OF THE PROJECT "ENCONTROS (IN)SEGUROS"}

doi:10.1136/sextrans-2013-051184.0856

'I F Gonçalves, "I C R Borges, ' $\mathrm{J}$ B Filho, ${ }^{2} \mathrm{H}$ Pereira, 'M E Saraiva. 'Portuguese League Against Aids, Lisboa, Portugal; 2 Portuguese League Against Aids/Beira Interior University, Lisboa, Portugal

Background This project arises from the lack of information about the reality of the sexual male workers in the city of Lisbon and from HIV/AIDS and other IST prevention projects, adapted to this target audience.

Methods Participating in the project 129 male sex workers, with an average age of 28.32 years $(S D=5,860)$. Most are single $(81.4 \%)$ and $48.8 \%$ identify themselves as homosexual or bisexual $(35.7 \%)$ $60.5 \%$ have a versatile role in sex, while $36.4 \%$ claim just be active. Instruments used to conduct this study: the socio-demographic questionnaire and the Questionnaire of Knowledge on HIV/AIDS which consists of 17 multiple-choice questions (yes, no, I don't know). This data was collected through an outreach strategy, with a field team operating with the audience, addressing the indoor sex work.

Results Male sex workers present high level of knowledge on HIV/ AIDS (average $=14.92, \mathrm{SD}=2.47$, range 0 a 17), however, have low levels of optimism (average $=20.89, \mathrm{SD}=4.53$, range $12-48$ ) and high levels of self-efficacy in condom use (average $=61.40, \mathrm{SD}=6.29$, range 13-65). The correlation analysis shows that higher levels of optimism were negatively associated with self-efficacy $(r=-0.203$, $p=0.029)$, indicating a moderate but significant negative relationship: the more optimistic, the less self-efficacy in condom use. Statistically significant differences were found in self-efficacy on condom use and sexual orientation; on nationality and condom use in oral sex and also sex role and self-efficacy in condom use.

Conclusions This Project has been of the utmost importance in preventing HIV/AIDS and other STI, by regular monitoring and routing of the target audience based on felt needs. The distribution of prevention-material and the relationship established with the audience points in that direction. It's extremely important for the prevention of HIV/AIDS and other STIs among sex workers, work with cognitive and behavioural variables, such as optimism and selfefficacy in condom use.

\section{P3.404 WITHDRAWN BY AUTHOR}

\section{P3.405 LEVELS OF ADVERTISED UNPROTECTED VAGINAL AND ORAL SEX OFFERED BY INDEPENDENT INDOOR FEMALE SEX WORKERS IN WEST YORKSHIRE, UK}

doi:10.1136/sextrans-2013-051184.0857

C Eccles, ${ }^{2} \mathrm{~J}$ Clarke. ${ }^{1}$ The University of Leeds Medical School, Leeds, UK; ${ }^{2}$ Centre for Sexual Health, Leeds General Infirmary, Leeds, UK

Background The objective was to assess the proportion of independent indoor female sex workers (FSW) in West Yorkshire, UK who advertise unprotected sex, and to investigate any association with factors that predict economic need.

Methods Data on whether independent indoor FSW (defined as those not advertising via an escort agency or through a parlour) offered unprotected sexual services, along with demographic data, was collected from 462 advertisement profiles of FSW in West Yorkshire from the website www.adultwork.com. One-way analysis of variance and chi-squared statistics were used to test the significance of associations between advertising unprotected vaginal and oral sex, offering anal sex, and FSW age, location and cost of services.

Results Unprotected vaginal sex was advertised by $8 \%$ of FSW, and unprotected oral sex by $74 \%$ of FSW. FSW offering unprotected vaginal sex had significantly lower hourly rates, were more likely to live in the more economically deprived areas of Wakefield and Bradford than in Leeds, and were more likely to offer anal sex.

Conclusion Advertised condom use for vaginal and oral sex by independent indoor FSW in West Yorkshire was significantly lower than rates of protected sex found in previous studies based in London and the south of England. FSW advertising unprotected vaginal sex were more likely to have predictors of greater financial need, such as lower hourly rates, provision of higher risk anal sex, and come from more economically deprived areas. They therefore represent a hard-to-reach target group for health promotion.

\section{P3.406 CONDOM USE TRENDS AMONG FEMALE SEX WORKERS IN VICITS STI CLINICS IN HONDURAS}

doi:10.1136/sextrans-2013-051184.0858

'N Artiles, ${ }^{2} \mathrm{~N}$ Farach, ${ }^{1} \mathrm{~F}$ Flores, ${ }^{3} \mathrm{M}$ Urquía, ${ }^{1} \mathrm{~F}$ Tinajeros. ${ }^{1}$ TEPHINET, Tegucigalpa, Honduras, ${ }^{2} C D C / C A R$, Tegucigalpa, Honduras, ${ }^{3}$ Ministerio de Salud, Tegucigalpa, Honduras 